\title{
Influence of magnitudes of negative pressures on dewatering behavior of ultra-soft clay
}

\author{
Jun Tong ${ }^{\text {i) }}$, Noriyuki Yasufuku ${ }^{\text {ii) }}$ and Kiyoshi Omine ${ }^{\text {iii) }}$ \\ i) Senior Engineer, Changjiang River Scientific Research Institute, Jiangda Road, Wuhan, 430010, China \\ ii) Professor, Department of Civil Engineering, Kyushu University, Fukuoka 819-0395, Japan \\ iii) Professor, Department of Civil Engineering, Nagasaki University, Nagasaki 852-8521, Japan
}

\begin{abstract}
The vacuum and siphon dewatering tests were performed to investigate the dewatering behavior of the high moisture content ultra-soft clay, respectively. All the tests are conducted in the small-scale tanks with plastic drainage board installed horizontally at the bottom. The influence of the magnitude of the negative dewatering pressures on the dewatering behavior of the dredged slurry was investigated. The test results show that the initial dewatering efficiency shows no significant difference when the slurry exists in the slurry-like state. Thereafter the dewatering efficiency increases with the magnitude of the applied dewatering pressure. The test results also show that the corresponding compression indexes in the pressure ranges from 0 to $30 \mathrm{kPa}$ and 30 to $80 \mathrm{kPa}$ are $0.33,0.3$, respectively.
\end{abstract}

Keywords: dredged slurry, laboratory test, dewatering, behavior

\section{INTRODUCTION}

A large quantity of dredged slurry is generated in modern cities around the world. There are urgent demands for developing alternatives to dispose and utilize the dredged material in an effective and environment-friendly manner. Typically, the disposal of the slurry becomes a social concern gradually. The material can be a valuable resource although much of it is currently disposed because of economic, logistical or environmental constraints. Whereas, in many countries disposal is becoming more and more difficult owing to the lack of space as well as environmental concerns. Therefore, developing techniques for dewatering to reducing the volume of sludge is of significant necessity. However, there is little laboratory study on the dewatering behaviour of the dredged slurry under the horizontal drainage condition (Umezaki, et al., 2004). It have been reported that fundamentally experimental investigation has been conducted on the feasibility of using the siphon method to dewatering the high-water-content dredged slurry in the laboratory (Tong, et al., 2010a). Thereafter, the siphon and vacuum comparative dewatering tests with horizontally installed plastic drainage plate was conducted to preliminarily investigate the dewatering and strength behaviour of the dredged mud, respectively (Tong, et al., 2010b and 2010c). The comparative study on the dewatering behaviour between the siphon, vacuum as well as the solar drying methods has also been carried out. Comparing the solar drying method, the siphon method is more efficient for dewatering the sludge with high water content, specifically at the initial dewatering stage (Tong, et al., 2010d). In this paper, the vacuum and siphon dewatering methods were performed to investigate the dewatering behaviour of the high moisture content slurry, respectively. The influences of the magnitude of the applied negative pressures on the dewatering behaviour of the dredged slurry are investigated.

\section{TEST SCHEME}

As shown in Table 1, the test scheme comprises 1 group of vacuum dewatering with the pressures of $30 \mathrm{kPa}, 60 \mathrm{kPa}, 80 \mathrm{kPa}$ and 1 group of siphon tests with the water head of $3 \mathrm{~m}, 5 \mathrm{~m}$, respectively. These tests are conducted to comparatively investigate the influences of the dewatering pressures on the dewatering behavior of the dredged slurry under vacuum and siphon conditions, respectively. The dewatering drainage is realized by the horizontally installed plastic drainage board. The initial water contents for all the tests were chosen as 1.2 times of the liquid limit, namely $93.5 \%$.

\section{TEST SAMPLE AND APPARATUS}

The test sample used in the study was dredged from Island city, Fukuoka city, Japan, and was passed through a $2 \mathrm{~mm}$ mesh sieve. Its basic physical properties are presented in Table 2 . The dredged slurry contains more than $25 \%$ clay $(<0.005 \mathrm{~mm})$ and $60 \%$ silt 
Table 1. Test scheme

\begin{tabular}{|c|c|c|c|c|}
\hline $\begin{array}{c}\text { Test } \\
\text { name }\end{array}$ & $\begin{array}{c}\text { Dewatering } \\
\text { method }\end{array}$ & $\begin{array}{l}\text { Pattern of } \\
\text { the } \\
\text { drainage } \\
\text { plate } \\
\text { installation }\end{array}$ & $\begin{array}{c}\text { Initial } \\
\text { water } \\
\text { content } \\
(\%)\end{array}$ & $\begin{array}{c}\text { Initial } \\
\text { dewatering } \\
\text { pressure } \\
(\mathrm{kPa})\end{array}$ \\
\hline$\frac{\mathrm{V}-30-1}{\mathrm{~V}-30-2}$ & \multirow{4}{*}{ Vacuum } & \multirow{6}{*}{ Horizontal } & \multirow{6}{*}{$\begin{array}{c}93.5 \\
\left(1.2 w_{\mathrm{L}}\right)\end{array}$} & 30 \\
\hline V-60-1 & & & & 60 \\
\hline V-60-2 & & & & 00 \\
\hline $\begin{array}{l}\mathrm{V}-80-1 \\
\mathrm{~V}-80-2 \\
\end{array}$ & & & & 80 \\
\hline$S-3 m$ & \multirow{2}{*}{ Siphon } & & & $30(3 \mathrm{~m})$ \\
\hline S-5m & & & & $50(5 \mathrm{~m})$ \\
\hline
\end{tabular}

The liquid and plastic limits are $72 \%$ and $26 \%$, respectively; the plasticity index is $46 \%$; and the specific gravity is 2.678. According to the Unified Soil Classification System, the soil sample is categorized as $\mathrm{MH}$. The illustration for the test apparatus is shown in Figure 1. The test apparatus is mainly comprised of acrylic tanks, a plastic drainage plates, connectors and plastic pipe. As shown in Fig.1 (c), the length, width and thickness of the drainage plate are $17 \mathrm{~cm}, 9.6 \mathrm{~cm}$ and $3.9 \mathrm{~mm}$, respectively. It is installed in the right center of the bottom of the tank along the length direction horizontally. For the vacuum dewatering tests, the applied vacuum pressure is $30 \mathrm{kPa}$. For the siphon dewatering tests, the $3 \mathrm{~m}$ and $5 \mathrm{~m}$ long plastic pipes full-filled with de-aired water are utilized to yield the initial water head differences, respectively. The PWP transducer is installed at the end of the piper to monitor the variation of the siphon suction during the dewatering process. During the process of the tests, a piece of wrap membrane is covered on the surface of the mud to alleviate the evaporation, which could be a major cause for yielding the cracks.

Table 2. Basic physical properties of soil sample

\begin{tabular}{ccccc}
\hline Gravity & $\begin{array}{c}\text { Natural } \\
\text { Water } \\
\text { specific }\end{array}$ & $\begin{array}{c}\text { Liquid } \\
\text { limit } \\
G_{S}\end{array}$ & $\begin{array}{c}\text { Plastic } \\
\text { limit } \\
(\%)\end{array}$ & $\begin{array}{c}\text { Plastic } \\
(\%)\end{array}$ \\
\hline 2.673 & $89.4-93.1$ & 77.9 & 36.7 & 41.2 \\
\hline
\end{tabular}

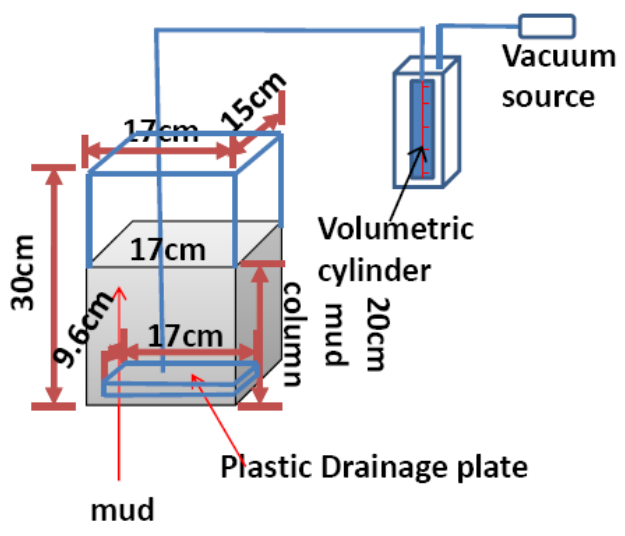

(1) Vacuum

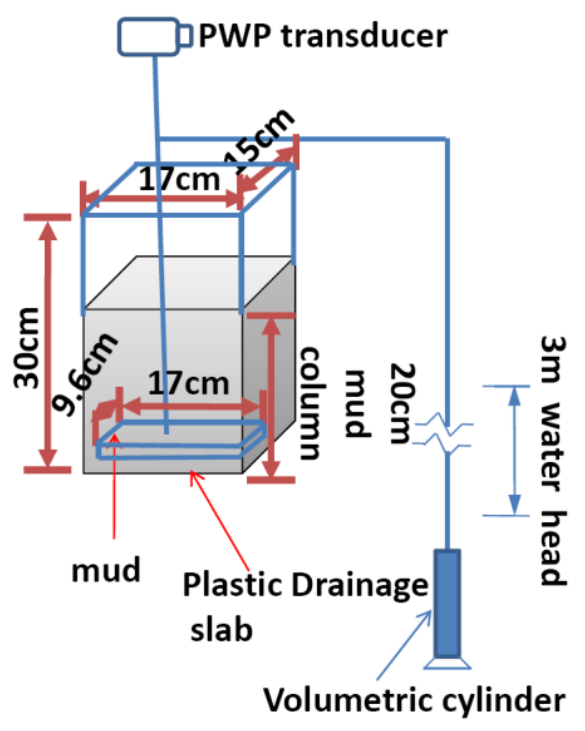

(2) Siphon

(a) Schematic diagram

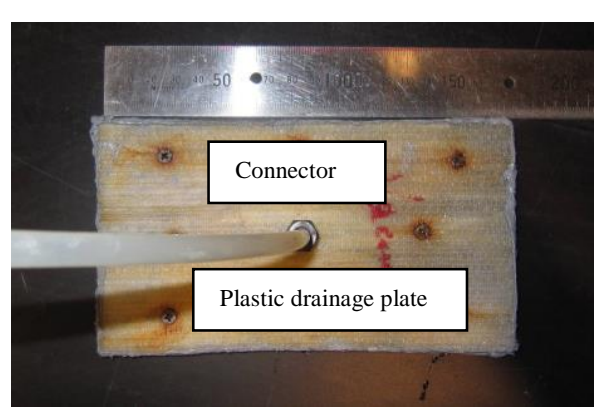

(b) Enlarged photo for the plastic drainage plate

Fig. 1. Test equipment

\section{TEST RESULTS AND ANALYSIS}

Fig.2 shows the comparison of dewatered volume versus time for the dredged slurry with different negative pressures. The variations of the dewatering volumes with the time show no distinct difference in the initial 15 hrs. However, the dewatered volume with 
greater magnitude becomes greater than that with less pressure gradually. Finally, the final dewatered volume under $60 \mathrm{kPa}$ vacuum pressure becomes 1.12 times greater than that with under $30 \mathrm{kPa}$ vacuum pressure. Whereas the final dewatered volume under $80 \mathrm{kPa}$ vacuum pressure is slightly greater (about 1.02 times) than that under $60 \mathrm{kPa}$ vacuum pressure. The dewatered volume is logarithmically proportional to the applied pressures.

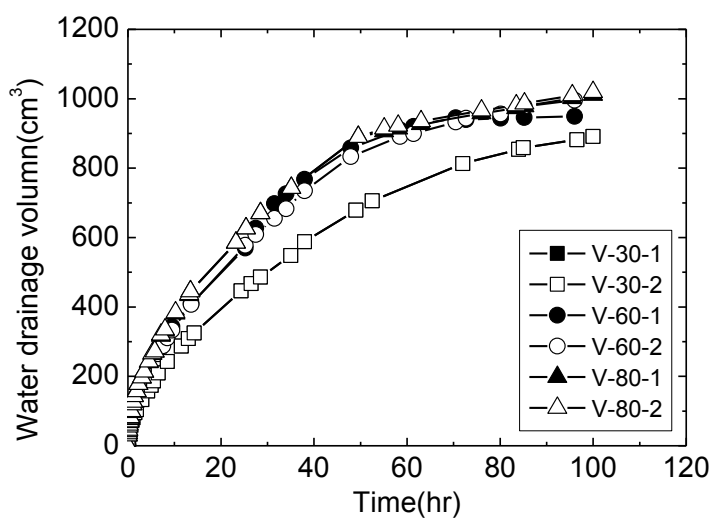

(a) Normal scale

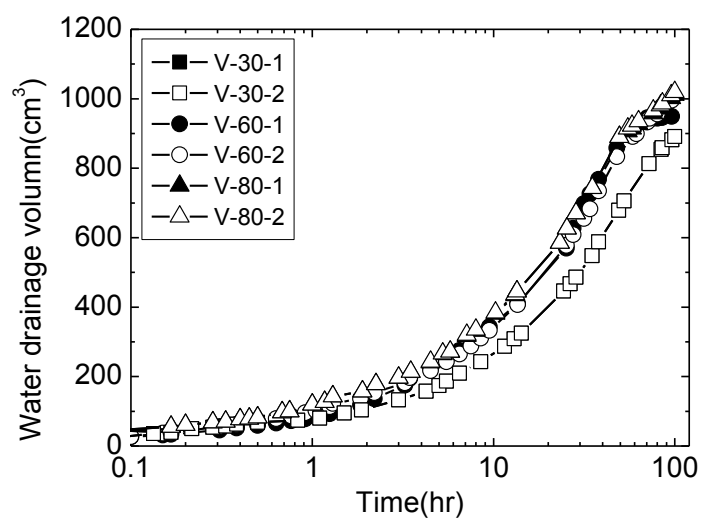

(b) Logarithmic scale

Fig.2. Comparison of dewatered volume versus time for the dredged slurry with different negative suctions

Fig. 3 and Fig.4 show the variation of the water contents and void ratio with time in the vacuum dewatering tests, respectively. All the curves can be generally divided into 2 stages. At the first stage, the dewatered volume decreases dramatically. Thereafter, the water content decreases slowly gradually. It could be also noticed there exists a very value, the dewatering velocity before the very value is significantly greater than that after it. The value is defined as the transitional value. Thus, it can be obtained from the figure that the transitional water contents for all the tests are around $w_{\mathrm{L}}$, the corresponding transitional void ratio is around 2.14. It falls in the range of transitional void ratios for the Singapore dredged slurry which varied between 2.13 and 2.36. One reason which may account for this phenomenon is that with the dewatering process, the soil is transfer from the slurry to the normal Terzaghi soil ${ }^{[5]}$. On the other hand, it was also observed in the tests when the average water content of the soil column are below the liquid limit, the cracks develop progressively, and then the vacuum suction can hardly maintain the initial value.

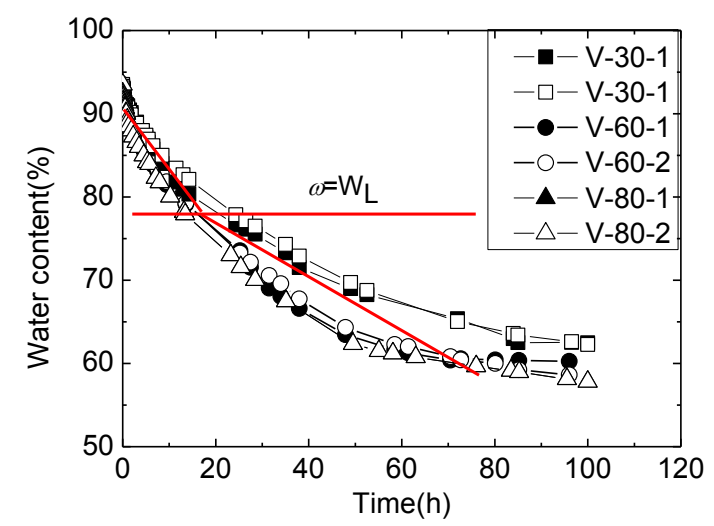

Fig.3. Comparison of water contents versus time for the dredged slurry with various vacuum suctions

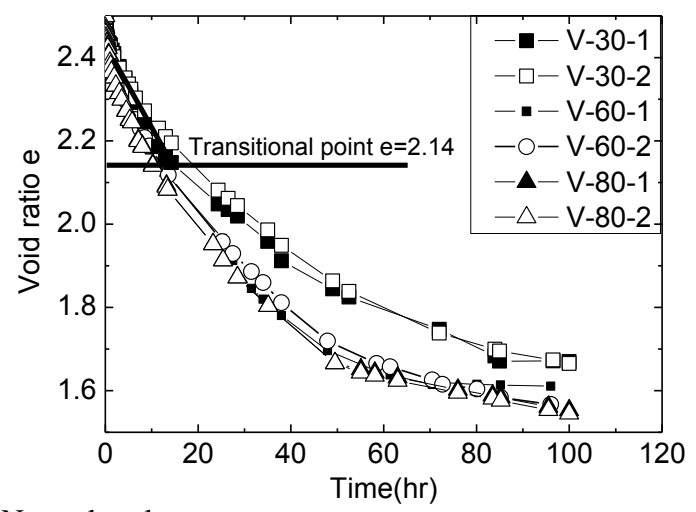

(a) Normal scale

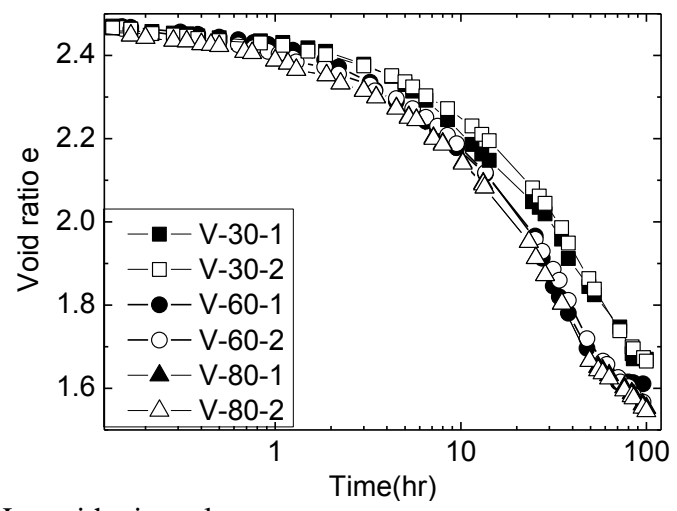

(b) Logarithmic scale

Fig.4. Comparison of void ratio versus time for the dredged slurry with various vacuum suctions

Fig. 5 shows the variation of the water content with time in the siphon dewatering tests. The initial water contents of the sludge for both tests are 93.5\%. The variation of the dewatering volumes with the time shows no distinct difference in the initial $15 \mathrm{hrs}$. Around $15 \mathrm{hr}$, the dewatered volume with $5 \mathrm{~m}$ siphon method becomes greater than that with $3 \mathrm{~m}$ siphon water head gradually. As shown in Fig.5, the average water 
contents of the soil column corresponding to the transitional point are $74.5,75.0 \%$, respectively, which of both are around the liquid limit. It is consistent with the principle of the vacuum dewatering tests that the transitional water content is also around the liquid limit. Fig.6 shows the variation of the PWP with time in the siphon dewatering tests. The siphon dewatering process could be generally categorized to 3 stages. At the first stage, the dewatered suction is equal to the siphon water heads correspondingly. Thereafter, it decreases slowly with time and remain a relative great value. It may account for this phenomenon that the alleviation of the siphon water head with more bubble due to the decrease of the water content. When the water content is below the liquid limit, the cracks develop progressively, and then the drainage plate would expose in the atmosphere through the cracks and little water head would be remained stable at generating the siphon dewatering pressure. Finally, the PWP water content of the sludge in the siphon method remains a small value. It may be inferred that the siphon method is specifically efficient for dewatering the sludge with high water content at the initial stage.

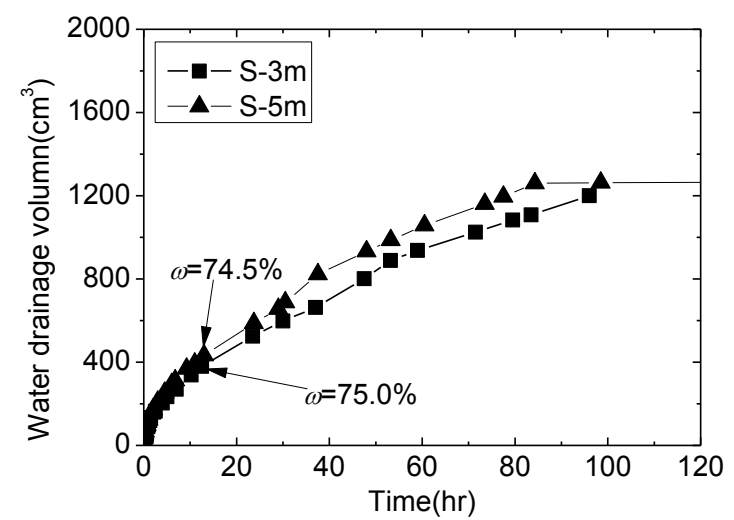

Fig.5. The variation of the water drainage volume with time in the $3 \mathrm{~m}$ and $5 \mathrm{~m}$ siphon water head

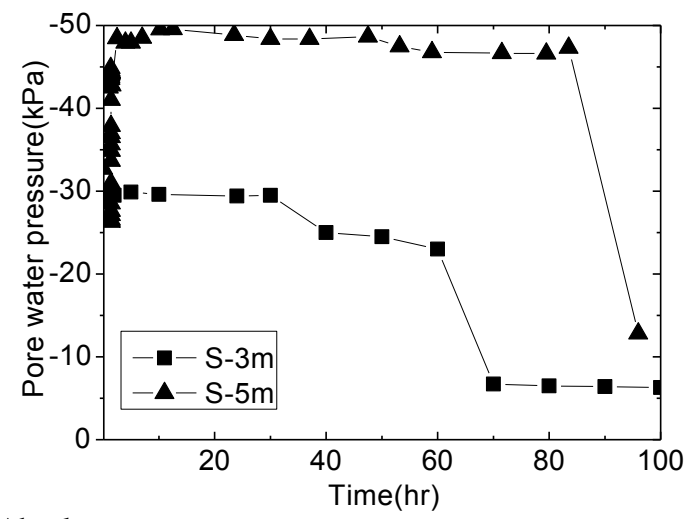

(a) Absolute pore water pressure

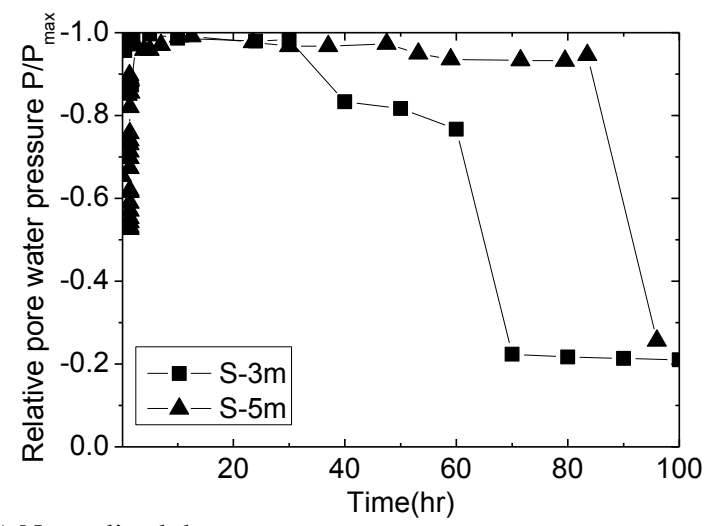

(b) Normalized the pore water pressure

Fig.6. The variation of the pore water pressure with time for different siphon water head

Fig.7 shows the final void ratio versus applied pressure in both the vacuum and siphon tests. The scatters represent the initial void ratio and the final void ratio of the soil sample under the vacuum dewatering pressures of $30 \mathrm{kPa}, 60 \mathrm{kPa}, 80 \mathrm{kPa}$, respectively. The initial void ratio of the soil sample is 2.49 . It is also showed that the corresponding compression indexes $\mathrm{C}_{\mathrm{c}}$ in the pressure ranges from 0 to $30 \mathrm{kPa}$ and 30 to 80 $\mathrm{kPa}$ are $0.33,0.3$, respectively. The different value of the $\mathrm{C}_{\mathrm{c}}$ value may due to the gradual gain of the effective stress with the development of the dewatering.

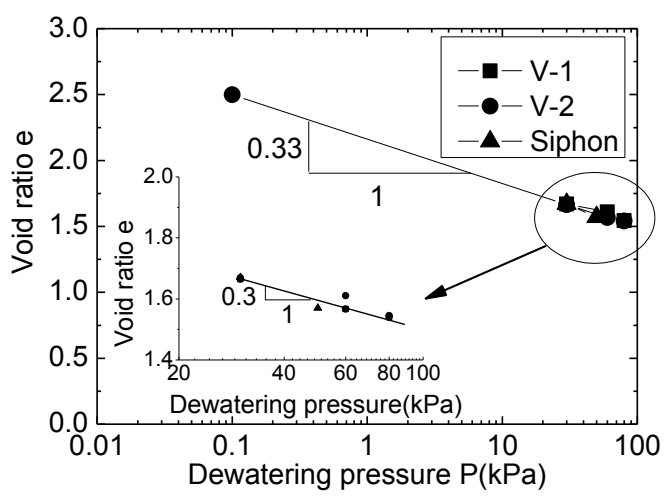

Fig. 7. Void ratio versus dewatered pressure

\section{CONCLUSION}

Dewatering tests were carried out on slurry-like soils with the moisture content of 1.2 times of the liquid limit under an applied negative pressure varying between 30 and $80 \mathrm{kPa}$. The following conclusions are drawn from the test results:

1. For both the vacuum and siphon dewatering tests, the initial dewatering efficiency shows no significant response difference to the variation of the variation of the magnitude of the pressure when the slurry exists in the slurry-like state. Thereafter the dewatering efficiency increase with the magnitude of the applied dewatering pressure.

2. For both the vacuum and siphon dewatering tests, it 
can be defined a threshold point that of which the dewatering behavior shows significant difference before and after the very value. In the study, the corresponding threshold water content is around the liquid limit $w_{\mathrm{L}}$. When the average water content of the soil column is less than the value, the magnitude of the negative pressure exhibit little influence on the efficiency of the dewatering, while greater than the value, the dewatering efficiency increases with the magnitude of the dewatering pressure.

3. It is shown that the corresponding compression indexes in the pressure ranges from 0 to $30 \mathrm{kPa}$ and 30 to $80 \mathrm{kPa}$ are $0.33,0.3$, respectively.

\section{REFERENCES}

1) Bo M.W., Choa V., and Wong K.S. (2002): Compression tests on a slurry using a small-scale consolidometer, Canadian Geotechnical Journal, 39(2): 388-398.
2) Tong J., Yasufuku N. and Omine K., et al. (2010a): Experimental study on an alternative method to dewater the dredged mud by siphon method. The 45th Japanese Geotechnical Symposium, Matsuyama, Japan: 771-772. (CD-ROM)

3) Tong J., Yasufuku N. and Omine K., et al. (2010b): Experimental study on the dewatering behavior of the dredged mud with horizontal drainage by siphon method. Geosynthetics Engineering Journal, 25: 267-270.

4) Tong J., Yasufuku N. and Omine K., et al. (2010c): Experimentally comparative study on the dewatering of the dredged mud by siphon and vacuum methods. Proceedings of the 7th International Symposium on Lowland Technology, Saga, Japan, 79-83.

5) Tong J., Yasufuku N. and Omine K., et al. (2010d): Comparative study on dewatering sludge with solar drying and siphon methods. The 3rd Japan-Korea Geotechnical Engineering Workshop.

6) Umezaki T., Kawamura T. and Kono T., et al. (2004): Dewatering test of dredged soil with high water content for trial design on practical work. Proceeding of 39th Japan National Conf. on Geotechnical Engineering, Niigata, Japan, 27-32 